\title{
Prevalence and factors associated with low back pain among school teachers residing in northern Dhaka city
}

\begin{abstract}
Low Back Pain (LBP) is known as a common musculoskeletal problem \& it is found a greater percentage among professionals. The purpose of the study was to find out the prevalence of LBP \& its associated factors among school teachers. A cross-sectional study was carried out comprising 69 male and 76 female with an age range between 25-60years old took part in this study. Results indicated that a greater percentage of school teachers found LBP. Factors like BMI, previous back injury, sleeping disturbance were responsible for LBP. However, there was no significant relationship found between LBP with office ergonomics. A knowledge program might be introduced among school teachers for creating awareness of factors related to LBP.
\end{abstract}

Keywords: low back pain, associated factors, school teachers, ergonomics
Volume 10 Issue 5 - 2018

Joyonty Akter, Mohammad Kamrujjaman, Abdul Maleque

Department of Physiotherapy, State College of Health Sciences, Dhaka, Bangladesh

Correspondence: Mohammad Kamrujjaman, Lecturer of Physiotherapy, State college of Health sciences, House-262/A, Road-27, Dhanmondi, Dhaka- I209, Bangladesh, Tel 0181951701 I, Email kamrujjamanI0@gmail.com

Received: October 01, 2018 | Published: October 08, 2018

\section{Introduction}

Low back pain (LBP) is a common musculoskeletal disorder in both the developed \& developing countries \& more than half of the worldwide population will experience LBP in their life. It is recognized as a very common health problem in exploiting people that play a major part in the quality of animation. In the United States, LBP is defined as a second most usual case of impairment among adults. ${ }^{1}$ It influences socioeconomic problem of individuals. ${ }^{2}$ LBP is now regarded as a top ten high burden diseases as higher than HIV, road injuries, tuberculosis, lung cancer, chronic obstructive, pulmonary disease, and preterm birth complication. ${ }^{3}$ Recent studies suggested that school teachers involved at a greater risk of musculoskeletal pain. ${ }^{4}$ LBP refers to pain or discomfort located in the bottom part of the back, which is recognized as the lumbar back. Some responsible factors like a study-related task, prolonged sitting, standing posture, and inappropriate furniture are the major cause of LBP for the school teacher. ${ }^{5,6}$ An overweight shows a high body mass indicator, which indicated poor subjective ill health. ${ }^{7}$ Individuals who suffered from LBP often create major physical, social and mental disruption that affects his/her occupation and decrease the quality of life (Tavaflan et al. 2007). Some other factors like insomnia, irritability, anxiety, and depression are also responsible for LBP. ${ }^{8}$ There were lacks of research published in our country on this issue. So, this study will be expected to determine the prevalence and the associated factors that responsible for LBP.

\section{Methodology}

It was a descriptive Cross-sectional study conducted among teachers from different school situated at Mohalhali, Khilkhet, Mirpur in northern Dhaka city. Study was carried out over six months from September 2016 to February 2017. The Study population consists of male and female school teachers with an age range of 25-60years old and who was employed for at least 5 months. Samples were selected purposively and data were collected through face to face interview with the interviewer-administered structured questionnaire. The collected data were checked thoroughly and strictly for any error or information missing and then analyzed by using the statistical software named "Statistical Package for Social Science" (SPSS-22). Before data collection, permission from the Ethical Committee of The State College of Health Sciences was acquired and a request letter will give over to the appropriate authorities of the study area for getting permission and seeking help for smooth access to data collection.

\section{Results}

The current study found \& Figure 1 shows that about $46 \%$ of school teachers complained LBP whereas about $54 \%$ of school teachers did not have LBP (Tables 1-6).

Table I Socio-demographic factors of respondents $[n=\mid 45]$

\begin{tabular}{lll}
\hline Variables & (n) & (\%) \\
\hline Age Range (In Years) & & \\
\hline 25 to 34 Years & 47 & 60 \\
35 to 44 Years & 40 & 27.6 \\
45 to 54 Years & 13 & 9 \\
55 to 64 Years & 5 & 3.4 \\
\hline Gender & & \\
\hline Male & 69 & 47.6 \\
Female & 76 & 52.4 \\
\hline Educational level & & \\
\hline Graduate & 44 & 30.3 \\
Post Graduate & 101 & 69.7 \\
\hline Monthly Income & & \\
\hline <30000 BDT & 55 & 37.9 \\
300000-60000 BDT & 64 & 46.2 \\
60000-90000 BDT & 14 & 9.7 \\
90000> BDT & 9 & 6.2 \\
\hline
\end{tabular}

Analysis of the socio-demographic characteristics and table I shows that age range 25 to 34 years were maximized $(n=87,60.0 \%)$ and mean age of the respondents was $34.4966( \pm 8$. 164). Among them, female participants were more than male where the majority $(n=101,69.7 \%)$ of the participants completed their post graduation \& the median of monthly income of the respondents was BDT 40,000. 
Table 2 Distribution of respondents by information related factors $(n=145)$

\begin{tabular}{|c|c|c|}
\hline Variables & (n) & (\%) \\
\hline \multicolumn{3}{|c|}{ Working hour in a day } \\
\hline$<5$ hours & 36 & 24.8 \\
\hline $5-10$ hours & 108 & 74.5 \\
\hline$>$ IOhours & I & 0.7 \\
\hline \multicolumn{3}{|c|}{ Teaching Experience } \\
\hline$<$ IYear & 9 & 6.2 \\
\hline I to 5 Year & 59 & 40.7 \\
\hline 5 to 10 Year & 32 & 22.1 \\
\hline$>10$ Year & 45 & 31 \\
\hline \multicolumn{3}{|c|}{ Sitting time during work } \\
\hline$<$ Ihour & 72 & 49.7 \\
\hline I-3 hour & 63 & 43.4 \\
\hline$>3$ hour & 10 & 6.9 \\
\hline \multicolumn{3}{|c|}{ Standing Time during work } \\
\hline$<3$ hours & 25 & 17.2 \\
\hline 3 to 5 hours & 84 & 57.9 \\
\hline$>5$ hours & 36 & 24.8 \\
\hline \multicolumn{3}{|c|}{ School work at home } \\
\hline Yes & 138 & 95.2 \\
\hline No & 7 & 4.8 \\
\hline \multicolumn{3}{|c|}{ Computer work } \\
\hline Yes & 85 & 58.6 \\
\hline No & 60 & 41.4 \\
\hline \multicolumn{3}{|c|}{ Sleep disturbance } \\
\hline Yes & 59 & 40.7 \\
\hline No & 86 & 59.3 \\
\hline \multicolumn{3}{|c|}{ Previous Back Injury } \\
\hline Yes & 26 & 17.9 \\
\hline No & 119 & 82.1 \\
\hline \multicolumn{3}{|c|}{ Job satisfaction } \\
\hline Yes & 115 & 79.3 \\
\hline No & 30 & 20.7 \\
\hline
\end{tabular}

Revealed that the majority $(n=108,74.5 \%)$ of respondents worked at 5 to 10 hours in a day. Among them, a greater percent $(40.7 \%)$ of respondents was I to 5 years of job experience. Most of them $(n=72,49.7 \%)$ sitting time in school at $<1$ hour where more than half $(n=84,57.9 \%)$ of the respondents standing time was at 3 to 5 hours and more than half of the respondents did not use a computer. Nearly all participants $(95.2 \%)$ worked school task in their household.A high percentage $(40.7 \%)$ of respondents was suffering from sleep disturbance. Maximum participants $(n=119,82.1 \%)$ did not possess any past back injury and most of $(\mathrm{n}=\mid \mathrm{I}, 5,79.3 \%)$ among the respondents had job satisfaction
Table 3 Distribution of respondents based on Ergonomics ( $n=145)$

\begin{tabular}{|c|c|c|}
\hline Variables & (n) & (\%) \\
\hline \multicolumn{3}{|c|}{ Seat $\&$ working table distance } \\
\hline Closely & 134 & 92.4 \\
\hline Not closely & 4 & 7.6 \\
\hline \multicolumn{3}{|c|}{ Adjustable back support } \\
\hline Yes & 113 & 77.9 \\
\hline No & 32 & 22.1 \\
\hline \multicolumn{3}{|c|}{ Using arm support } \\
\hline Yes & 62 & 42.8 \\
\hline No & 83 & 57.2 \\
\hline
\end{tabular}

Regarding the ergonomics analysis, maximum $(\mathrm{n}=134,92.4 \%)$ respondent closely maintained their seat from working table. Most of $(\mathrm{n}=113,77.9 \%)$ among them used the adjustable backrest support and more than half $(\mathrm{n}=83$, $57.2 \%$ ) of the respondents reported not using arm support.

Table 4 Information related to pain characteristics $(n=67)$

\begin{tabular}{lcc}
\hline Variables & (n) & (\%) \\
\hline Suffering time & & \\
\hline < I month & I & 1.5 \\
I to 6 month & 5 & 7.5 \\
3 to I2 month & 7 & 10.4 \\
$>$ I year & 54 & 80.4 \\
\hline Severity of pain & & \\
\hline Mild & 27 & 40.3 \\
Moderate & 29 & 43.3 \\
Severe & 11 & 16.4 \\
\hline Pattern of pain & & \\
\hline Temporary & $4 \mathrm{I}$ & 61.2 \\
Continuous & 18 & 26.9 \\
Severe & 8 & 11.9 \\
\hline Radiating pain & & \\
\hline Sharp pain & 37 & 55.2 \\
Dall pain & 3 & 4.5 \\
Thrombing pain & 13 & 19.4 \\
Burning Pain & 7 & 10.4 \\
Numbness & 7 & 10.4 \\
\hline & & \\
\hline
\end{tabular}

Revealed that highest percent $(n=54,80.4 \%)$ of participants complained suffering of pain for more than one year and maximum had mild $(40.3 \%)$ and moderate $(43.3 \%)$ level of pain with temporary pattern. most of them $(n=37$, $55.2 \%)$ complained sharp radiating pain. 
Table 5 Association between LBP with age, sex, BMI, Previous back injury, and arm support in sitting position

\begin{tabular}{|c|c|c|c|c|}
\hline \multirow{2}{*}{ Variables } & \multicolumn{2}{|c|}{ Low Back Pain } & \multirow{2}{*}{ Total } & \multirow{2}{*}{ Chi -Square test } \\
\hline & Present & Absent & & \\
\hline \multicolumn{5}{|l|}{ Age Range } \\
\hline 25 to 34 Years & 37 (42.5\%) & $50(57.5 \%)$ & $87(100.0 \%$ & \multirow{4}{*}{$\begin{array}{l}\chi^{2}=4.859 \\
d f=3 \\
P=0.182\end{array}$} \\
\hline 35 to 44 Years & $24(60.0 \%)$ & $16(40.0 \%)$ & $40(100.0 \%)$ & \\
\hline 45 to 54 Years & $4(30.8 \%)$ & $9(69.2 \%)$ & $13(100.0 \%)$ & \\
\hline 55 to 64 Years & $2(40.0 \%)$ & $3(60.0 \%)$ & $5(100.0 \%)$ & \\
\hline \multicolumn{4}{|l|}{ Sex } & \multirow{3}{*}{$\begin{array}{l}\chi^{2}=3.850 \\
d f=I \\
p=0.50\end{array}$} \\
\hline Male & $26(37.7 \%)$ & $43((62.3 \%)$ & $69(100.0 \%)$ & \\
\hline Female & $4 \mathrm{l}(53.9 \%)$ & 35 (46.1\%) & $76(100.0 \%)$ & \\
\hline \multicolumn{4}{|c|}{ Body Mass Index } & \multirow{5}{*}{$\begin{array}{l}\chi^{2}=12.618 \\
d f=3 \\
p=0.006 *\end{array}$} \\
\hline$<18.5$ & $0(0.0 \%)$ & $3(100.0 \%)$ & $3(100.0 \%)$ & \\
\hline $18.5-24.9$ & 27 (36.5\%) & 47 (63.5\%) & $74(100.0 \% 0$ & \\
\hline $25-29.9$ & 38 (62.3\%) & $23(37.7 \%)$ & $61(100.0 \%)$ & \\
\hline$>30$ & $2(28.6 \%)$ & 5 (7I.4\%) & $79100.0 \%)$ & \\
\hline \multicolumn{4}{|c|}{ Previous Back Injury } & \multirow{3}{*}{$\begin{array}{l}\chi^{2}=15.225 \\
d f=I \\
p=0.000 *\end{array}$} \\
\hline Yes & 21 (80.8\%) & 5 (19.2\%) & $26(100.0 \%)$ & \\
\hline No & $46(38.7 \%)$ & $73(61.3 \%)$ & $119(100.0 \%)$ & \\
\hline \multicolumn{4}{|c|}{ Teaching experience } & \multirow{5}{*}{$\begin{array}{l}\chi^{2}=3.562 \\
d f=3 \\
p=.313\end{array}$} \\
\hline$<$ I Year & 6 & 3 & 9 & \\
\hline I to 5 Year & 24 & 35 & 59 & \\
\hline 5 to 10 year & 13 & 19 & 32 & \\
\hline$\varnothing 10$ Year & 24 & 21 & 45 & \\
\hline \multicolumn{4}{|c|}{ Disturbance during sleeping ${ }^{a}$} & \multirow{2}{*}{$\begin{array}{l}\chi^{2}=6.884 \\
d f=1\end{array}$} \\
\hline Yes & 35 (59.3\%) & $24(40.7 \%)$ & $59(100.0 \%)$ & \\
\hline No & $32(37.2 \%)$ & $54(62.8 \%)$ & $86(100.0 \%)$ & $\mathrm{p}=.01 \mathrm{I}^{*}$ \\
\hline \multicolumn{5}{|c|}{ Doing School work at home ${ }^{a}$} \\
\hline Yes & $63(45.7 \%)$ & 75 (54.3\%) & & $\begin{array}{l}\chi 2=.354 \\
d f=I\end{array}$ \\
\hline No & $4(57.1 \%)$ & $3(42.9 \%)$ & & $\mathrm{p}=.704$ \\
\hline \multicolumn{5}{|c|}{ Adjustable Back support ${ }^{a}$} \\
\hline Yes & 49 (43.4\%) & $64(56.6 \%)$ & & $\begin{array}{l}\chi^{2}=1.666 \\
d f=1\end{array}$ \\
\hline No & $18(56.3 \%)$ & 14 (43.8\%) & & $\mathrm{p}=.231$ \\
\hline \multicolumn{5}{|c|}{ Job Satisfaction ${ }^{a}$} \\
\hline Yes & $52(45.2 \%)$ & $63(54.8 \%)$ & & $\begin{array}{l}\chi^{2}=.219 \\
d f=I\end{array}$ \\
\hline No & 15 (50\%) & 15 (50\%) & & $p=.684$ \\
\hline
\end{tabular}

$p$-value reached from chi-square. 'a' indicated for using of Fisher's exact Test. Mark represents a significant association of LBP with BMI ( $\mathrm{p}$-value 0.006$)$, Previous back injury ( $p$-value 0.000$)$ and sleeping disturbance ( $p$-value.0II) 
Table 6 Associated Factor of LBP among the respondents $(n=145)$

\begin{tabular}{lllll}
\hline \multirow{2}{*}{ Variables } & \multicolumn{2}{l}{ Low back pain } & \multirow{2}{*}{ t-Value } & p- value \\
\cline { 2 - 3 } & Present Mean \pm SD & Absent Mean \pm SD & & \\
\hline Age & $34.6716 \pm 7.28924$ & $34.3462 \pm 8.89159$ & 0.239 & 0.812 \\
BMI & $24.9984 \pm 2.85967$ & $24.2359 \pm 3.65918$ & 1.381 & 0.169 \\
Monthly Income & $49674 \pm 29641.96116$ & $24.2359 \pm 3.65918$ & 2.01 & $.046 *$ \\
Sitting time & $2.2687 \pm 4.23310$ & $2.0321 \pm 1.29017$ & 0.469 & 0.64 \\
Standing time & $4.8209 \pm 1.50429$ & $4.5449 \pm 1.33918$ & 1.169 & 0.244 \\
Working duration & $6.7239 \pm 1.34639$ & $6.5641 \pm 1.33231$ & 0.716 & 0.475 \\
\hline
\end{tabular}

$t$-value reached from independent sample t-test. *Mark represents the significance of sample t-test. The study found significant association of LBP with monthly family income ( $p$-value 0.046).

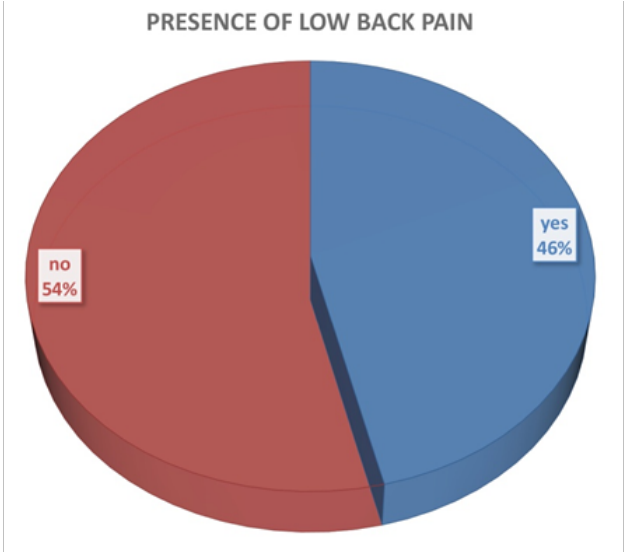

Figure I Prevalence of LBP among the respondents.

\section{Discussion}

The present study was undertaken to determine the prevalence of LBP and its associated factors among school teachers. The result of the current study indicated that LBP is a common musculoskeletal disorder found in school teachers \& its prevalence was $46.2 \%$ among 145 participants. Age group 25 to 36years old reported with LBP in a high percentage where female school teachers were suffering more than male but there was no significant association of LBP with age \& sex in this study. The previous study found age group 40 to 59 years old had a majority of LBP \& female teachers were three times more experienced LBP than male teachers and significant association found between LBP and sex. ${ }^{9}$ Other studies stated that a higher prevalence rate of LBP found in female teachers than male. ${ }^{6,10}$ On the other hand, a study stated by Jin et al. (2004), younger teachers are at more risk for developing LBP. The current study found more than two third of the participants were satisfied with their job and there was no significant relation of LBP with Job satisfaction, but the other study found the person with LBP who had a mild and moderate level of Job satisfaction..$^{10}$ This study initiated that no relation found between job experience and LBP. Past study stated that the longer the years of practice, the greater the risk of having LBP and length of employment seemed to be significantly associated with the prevalence of LBP for the school teachers. ${ }^{10}$ Some studies demonstrated that static posture \& prolonged sitting could be risk factors for LBP (Omokhodion et al. 2003; Pope et al. 2002). The study found a greater risk of LBP occurrence in teachers who had prolonged sitting, prolonged standing, long period of working hours with computers, \& correcting examination papers (Mohammad et al. 2014) ${ }^{10}$ But current study found that there was no significant relation of LBP with sitting and standing time. Revealed that a number of school teachers were suffering LBP who had a history of back injury and there was a highly significant relationship between LBP with a back injury and another study showed that history of injury in the lower back had the significant impact on the back pain. Ozguler et al., ${ }^{11}$ stated that teachers who had previous back injury were 1.96 times to develop LBP compared who had no history of LBP. The study also revealed that a greater percent of the school teacher had normal body weight and less than half of the participants had overweight and a significant relation found between BMI and LBP. A recent study conducted among school teachers in Botswana and demonstrated that BMI was not significantly associated with LBP. ${ }^{4}$ Less than half of the participants had LBP who had the history of sleep disturbance where a significant association was seen in LBP with sleep disturbance, but a study found in Ethiopia, teachers who had been disturbed during sleeping were 1.91 times more likely to experience LBP when compared to those who were not disturbed during sleeping. The possible reason for the difference could be those who were disturbed during sleeping, lack sufficient rest than those who did not (Beyen et al. 2013). ${ }^{9}$ Nearly all teachers work at home for school purpose and a greater percentage had not used computer work in this subject. Different working condition \& demands of school teachers (teaching, assessing students, homework, correcting examination papers \& working with computers) that require prolonged sitting and standing may be considered as a risk factor for MSDs. ${ }^{6}$ In ergonomics, this study indicated that about $92.4 \%$ of school teacher maintain closed the distance between the seat and working table and more than two third of the participants used back support. A study conducted by Yue et al., ${ }^{5}$ stated that significant association was found among uncomfortable back support and the prevalence of LBP. Maximum participants' pain persists $>1$ year where most of them had a mid and a moderate level of pain with an intermittent pattern. Sharp radiating was the most common pattern of pain. School teachers were considered to have a widely varied prevalence rate of LBP, ranging from $17.7 \%$ in Japan to $53.3 \%$ in Brazil to $59.2 \%$ in China \& $6 \%$ in the United States (Ono et al. 1997; Grant et al. 1995).

\section{Conclusion}

It is concluded that the prevalence of LBP was fairly high among school teachers. Factors such as BMI, previous back injury, \& sleeping disturbance were associated with the prevalence of LBP among school teachers. There were no significant relations found between LBP with ergonomics. Higher monthly income teachers had higher rates of LBP compared to low income teachers. Some preventive strategies such maintain body weight; fairness of stress and comfortable work related 
environment will help to reduce the incidence of LBP in the school teacher population.

\section{Acknowledgements}

We, are the authors acknowledge the support provided by the Physiotherapy Department of State College of Health Sciences.

\section{Conflict of interest}

Authors of the article declare that there is no conflict of interest regarding this article.

\section{References}

1. Stewart WF, Ricci JA, Chee E, et al. Lost Productive time \& cost due to common pain conditions in the US workforce. Journal of the American Medical Association. 2003;290(18):2443-2454.

2. Kilbom S, Armstrong T, Buckle P, et al. Musculoskeletal disorders: Work-related risk factors and prevention. International Journal of Occupational and Environmental Health. 1996;2:239-246.

3. Rahman HWA, Qahtani AL, Salem HI, et al. Magnitude and risk factors of low back pain among Saudi teachers in Abha City, Saudi Arabia. Medicine Journal of Cairo University. 2016;84:87-92.

4. Erick PN, Smith DR. Low back pain among school teachers in Botswana, prevalence and risk factors. BioMed Central Musculoskeletal Disorders. 2014; 15:1471-2474.
5. Yue P, Liu F, Li L. Neck/shoulder pain and low back pain among school teachers in China, prevalence and risk factors. BioMed Central Public Health. 2012;12(1):789.

6. Cardoso JP, Ribeiro IDQB, Araujo TMD, et al. Prevalence of musculoskeletal pain among teachers. Revista Brasileira de Epidemiologia. 2009;12(4):1-10.

7. Wells N. Back pain. Office Health Economics. 1985:234-235.

8. Clairborne N, Vandenburgh H, Krause TM, et al. Measuring quality of life changes in individuals with chronic low back conditions: a back educations program evaluation. Evaluation Programme plan. 2002;25:61-70.

9. Beyen TK, Mengestu MY, Zele YT. Low back pain and associated factors among teachers in Gondar Town, North Gondar, Amhara Region, Ethiopia. Occupational Medicine \& Health Affairs. 2013;1(5):127.

10. Mohammad Mohseni Bandpei A, et al. Occupational Low Back Pain in Primary and High School Teachers: Prevalence and Associated Factors. Journal of Manipulative and Physiological Therapeutics. 2014;37(9):702-708.

11. Ozguler A, Leclerc A, Landre MF, et al. Individual and occupational determinants of low back pain according to various definitions of low back pain. J Epidemiol Community Health. 2000;54:215-220. 